\title{
Динамическая характеристика пространственного развития экономики Центрально-Чернозёмного макрорегиона
}

\author{
Владыка М.В., Солнцев Д.Р. \\ Белгородский государственный национальный исследовательский университет, \\ Россия, 308015, г. Белгород, ул. Победы, 85 \\ Департамент агропромышленного комплекса и воспроизводства окружающей среды \\ Белгородской области, Россия, 308015, г. Белгород, ул. Попова, 24 \\ E-mail: vladyka@bsu.edu.ru, solncev@belapk.ru
}

\begin{abstract}
Аннотация
В данной статье представлены ключевые показатели развития областей Центрально-Черноземного макрорегиона. Выделена отраслевая специализация по Белгородской области, а также проведён анализ условий, тенденций и перспектив устойчивого развития макрорегиона с учётом диверсификации экономического развития областей. Исследование показывает, что современная пространственная политика развития аграрно-индустриальных регионов, развивающихся в условиях необходимости преодоления центростремительных тенденций, должна предусматривать приоритетное развитие периферийных территорий. Выделены основные тенденции и перспективы пространственного развития исследуемой территории: концентрация экономического роста в ограниченном числе центров, рост социально-экономической роли городов; стабилизация численности населения в крупных субъектах Российской Федерации и закрепление перманентного характера в общей тенденции снижения численности населения периферийных территорий; сокращение межрегиональных социально-экономических диспропорций в рамках глобальных центростремительных тенденций; трансформация пространственной организации экономики в виде транспарентности экономических процессов. Согласно проведенному в статье анализу, объединение регионов в один макрорегион положительным образом влияет на основные показатели развития.
\end{abstract}

Ключевые слова: экономика, регион, динамическая несогласованность, валовой региональный продукт, стратегия пространственного развития страны, пространственные эффекты.

Благодарности: исследование выполнено в рамках государственного задания НИУ «БелГУ» FZWG2020-0016 (0624-2020-0016), тема проекта «Фундаментальные основы глобальной территориальноотраслевой специализации в условиях цифровизации и конвергенции технологий».

Для цитирования: Владыка М.В., Солнцев Д.Р. 2020. Динамическая характеристика пространственного развития экономики Центрально-Чернозёмного макрорегиона. Экономика. Информатика. 47 (4): 679 688. DOI 10.18413/2687-0932-2020-47-4-679-688.

\section{Dynamic characteristics of the spatial development of the economy of the Central Black Earth macro-region}

\author{
Vladyka M.V., Solntsev D.R. \\ Belgorod National Research University, 85 Pobedy St, Belgorod, 308015, Russia \\ Department of the Department of Agroindustrial Complex and Environmental Reproduction \\ of the Belgorod Region, 24 Popova St, Belgorod, 308015, Russia \\ E-mail: vladyka@bsu.edu.ru, solncev@belapk.ru
}

\begin{abstract}
This article presents the key indicators of the development of the regions of the Central Black Earth Macroregion. Particular attention is paid to the heritage of retrospective aspects describing the interaction of the center and the
\end{abstract}


periphery, contributing to the formation and reproduction of socio-economic differentiation between them, revealing the diagnostic features and spatial and economic specifics of the processes of functioning and development of macroregional territories. Sectoral specialization in the Belgorod region is highlighted, as well as an analysis of conditions, trends and prospects for sustainable development of the macroregion, taking into account the diversification of economic development of the regions. The study shows that the modern spatial policy for the development of agro-industrial regions, developing in the context of the need to overcome centripetal trends, should provide for the priority development of peripheral territories. Main trends and perspectives of spatial development in the study area: focus of economic growth in a limited number of centers, the growing social and economic role of cities; the stabilization of population in the major regions of the Russian Federation and consolidation of a permanent character in the general trend of decline in the population of peripheral areas; decrease of regional socio-economic disparities in the global centripetal trends; the transformation of the spatial organization of the economy in the form of transparency of economic processes. According to the analysis carried out in the article, the unification of regions into one macro-region has a positive effect on the main indicators of development.

Keywords: economy, region, points of growth, gross regional product, import, export, strategy of spatial development of the country, spatial effect.

Acknowledgements: the research was carried out within the framework of the state assignment of NRU BelSU FZWG-2020-0016 (0624-2020-0016), the topic of the project "Fundamental foundations of global territorial and industry specialization in the context of digitalization and technology convergence".

For citation: Vladyka M.V., Solntsev D.R. 2020. Dynamic characteristics of the spatial development of the economy of the Central Black Earth macro-region. Economics. Information technologies. 47 (4): 679-688 (in Russian). DOI 10.18413/2687-0932-2020-47-4-679-688.

\section{Введение}

В современной региональной экономике роль диагностики параметров развития территорий неуклонно возрастает, при этом на первый план выходят вопросы не только отслеживания индикаторов социально-экономического плана, но и характеристик пространственного типа, что требует разработки действенного инструментария по выявлению, верификации и экономико-управленческой интерпретации существующих региональных проблем и ситуаций. Особенностью пространственного развития макрорегионов является не только масштаб природного и производственного развития, но и немаловажное значение имеет масштаб финансово-экономического и инфраструктурного потенциала. $\mathrm{C}$ целью определения направлений модернизации и расширения их инфраструктуры принята Стратегия пространственного развития страны до 2025 года, направленная на совершенствование системы расселения и территориальной организации экономики, в том числе за счет проведения эффективной государственной политики регионального развития [Об утверждении Стратегии пространственного развития РФ...]. Основой для принятия стратегически важных решений по развитию территорий, в соответствии с принятым Постановлением Правительства Российской Федерации от 13.02.2019 г., являются приоритеты национальных проектов. Обеспечение сбалансированного развития макрорегионов Российской Федерации основано на принятии мер опережающего развития депрессивных территорий, а в числе ключевых критериев выступает сокращение межрегиональных различий в уровне и качестве жизни.

\section{Объекты и методы исследования}

Методологической основой статьи выбран системно-функциональный подход, дающий возможность обобщения и синтеза исследуемых процессов развития макрорегиона. Кроме того, он позволяет рассмотреть происходящие процессы пространственного развития в их взаимосвязи с диалектическим развитием. 


\section{Основные результаты исследования}

Каждый субъект Российской Федерации имеет свои характеристические особенности и перспективные социально-экономические специализации. Центрально-Черноземный макрорегион - это один из наиболее развитых и густонаселённых субъектов территориального деления Российской Федерации. Его особенности проявляются в том, что он является крупнейшей железорудной базой и характеризуется высокой степенью развития АПК, как аграрно-индустриальная территория, традиционно богатая плодородными почвами, преобладающими на всей его территории. Кроме того, этот макрорегион богат природными ресурсами: железные, титановые и медно-никелевые руды; бокситы; фосфориты; огнеупорные глины; природные строительные материалы (камень, щебень, песок). По основным показателям развития Центрально-Чернозёмного макрорегиона можно выделить его достаточно успешное развитие, что подтверждают индексы производства, приведенные на рисунке 1.

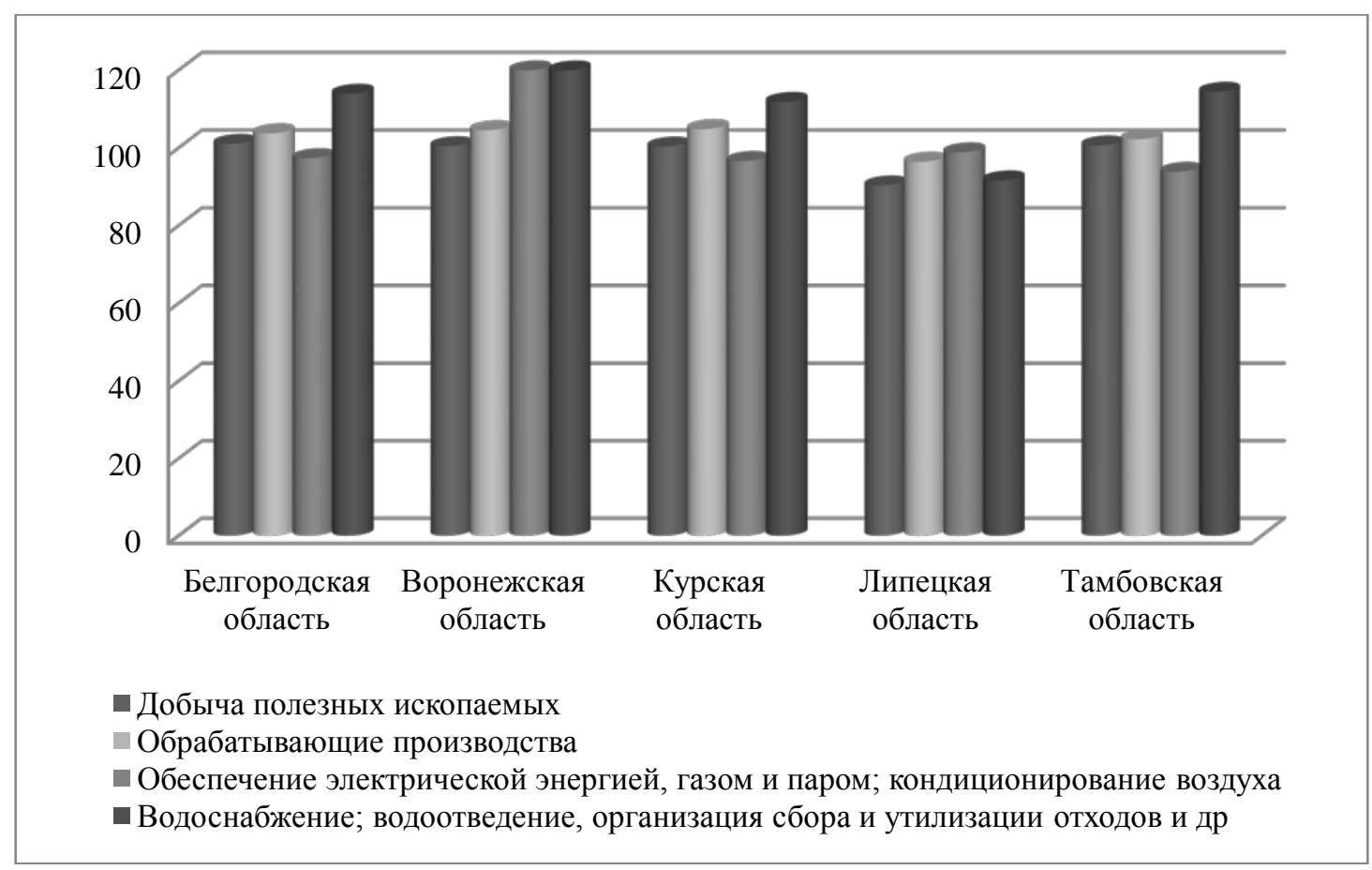

Рис. 1. Динамика индексов производства Центрально-Чернозёмного макрорегиона по виду деятельности в 2019 году, \% [Белгородская область в цифрах, 2020]

Fig. 1. Dynamics of production indices of the Central Black Earth Macro-region by type of activity in 2019, $\%$ [Belgorod region in numbers, 2020]

Согласно данным, представленным на рисунке 1, Воронежская область занимает лидирующее положение по добыче полезных ископаемых и результатам работы обрабатывающих производств. По добыче полезных ископаемых Белгородская область занимает второе место и по этим показателям и входит в число индустриальных и сельскохозяйственных регионов Российской Федерации [Владыка, Горбунова, Ермаченко, 2019]. Характеризуя Центрально-Чернозёмный район, можно выделить Западный и Восточный подрайоны, имеющие разные отрасли специализации в промышленности. Первый включает Курскую и Белгородскую области, специализирующиеся на черной металлургии, металлообработке, горнорудной и легкой промышленности. Но для всех областей характерно развитие АПК комплексов и на высоком уровне находится растениеводство и животноводство. В Белгородской, Воронежской и Тамбовской областях в большей степени развито животноводство, в Курской области - растениеводство. Активное развитие сельского хозяйства предопределено тем, что более 80 \% земли здесь - плодородный чернозем (рис. 2). 


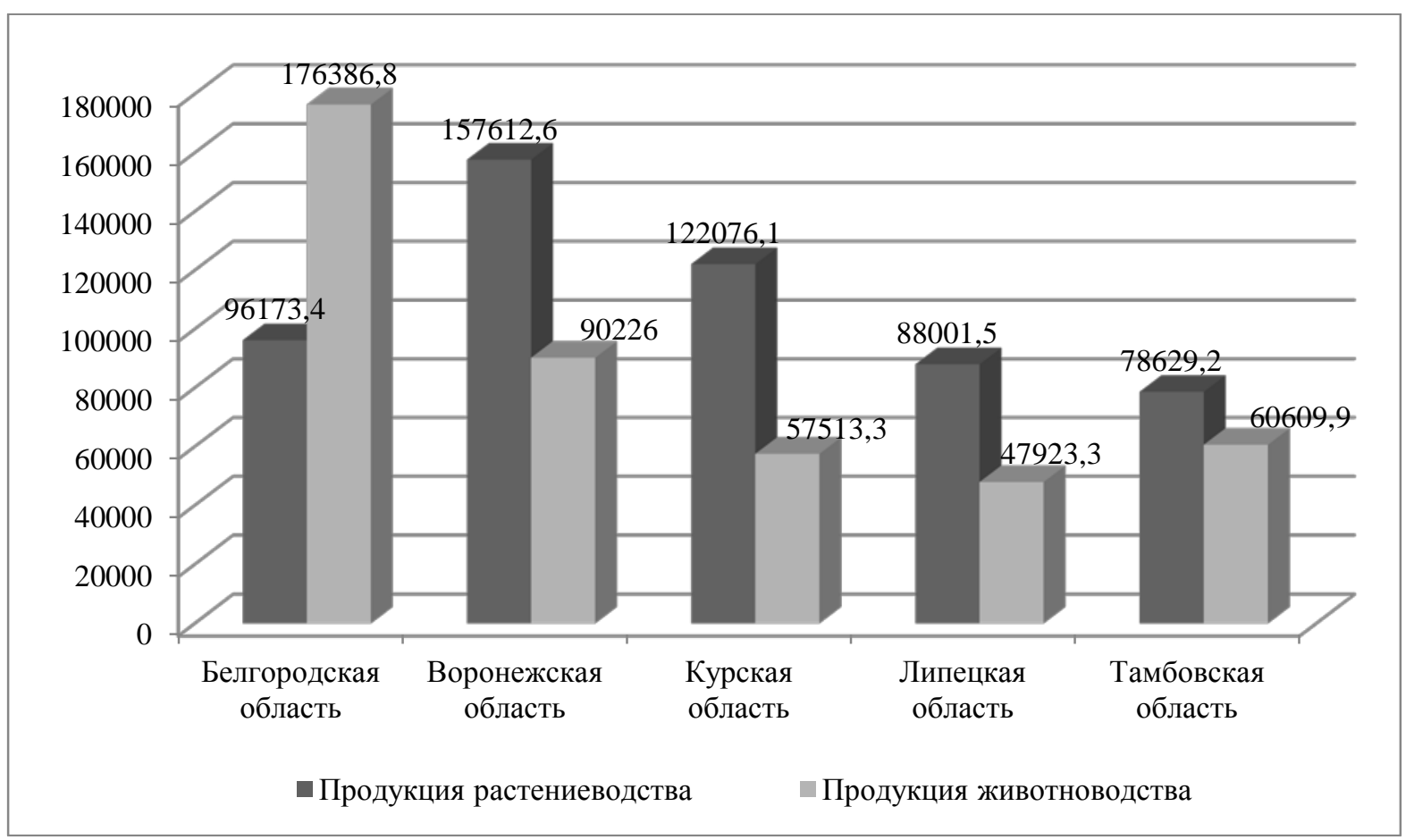

Рис. 2. Продукция растениеводства и животноводства Центрально-Чернозёмного макрорегиона в 2019 году, млн руб. [Белгородская область в цифрах, 2020]

Fig. 2. Crop production and livestock production of the Central Black Earth Macro-region in 2019, million rubles [Belgorod region in numbers, 2020]

Согласно данным, представленным на рисунке 2, Белгородская область занимает лидирующее положение по животноводству - 176386,8 млн руб., второе место заняла Воронежская область - 90226,0 млн руб. и третье - Тамбовская область - 60609,9 млн руб. По продукции растениеводства в 2019 году лидирующее положение заняла Воронежская область, на которую приходилось 157612,6 млн руб. Проанализировать нагрузку на факторы производства можно исходя из действующей в России системы налогообложения, сложившейся структуры производственного потенциала и влияния на экономику страны в целом. Для обобщающей характеристики региональной экономики применяется показатель сальдированного финансового результата экономической деятельности (рис. 3).

На рисунке 3 наглядно видно, что Белгородская область по финансовым результатам значительно превосходит Воронежскую, Курскую и Тамбовскую области. Незначительно уступает ей по этому показателю Липецкая область. Важнейшим показателем количественной и качественной характеристики экономики является ВРП, динамика которого по Белгородской области представлена на рисунке 4.

Представленные на рисунке 4 показатели свидетельствуют, что валовая прибыль формируется преимущественно в производственном секторе, на фоне снижения доли оплаты труда наёмных работников. Основным фактором, влияющим на социально-экономическую асимметрию, является «качество жизни населения». Различный уровень жизни населения региона формируется вследствие различия темпов экономического роста. Следствием этого формируются демографические различия, степень урбанизации, появляются социальноэкономические диспропорции.

Важной характеристикой развития региональных систем является показатель валовых доходов, позволяющий увидеть реальные производственные показатели, так как термин «валовая» указывает на то, что показатель определен до вычета потребления основного капитала [Клейнер, 2015]. Характеризуя развитие Белгородской области, можно отметить сочетание народнохозяйственных, отраслевых и региональных интересов, позволяющих 
добиваться доминирующей роли конкретных форм и методов осуществления сбалансированности пространственного развития в динамичной конкурентной среде (рис. 5).

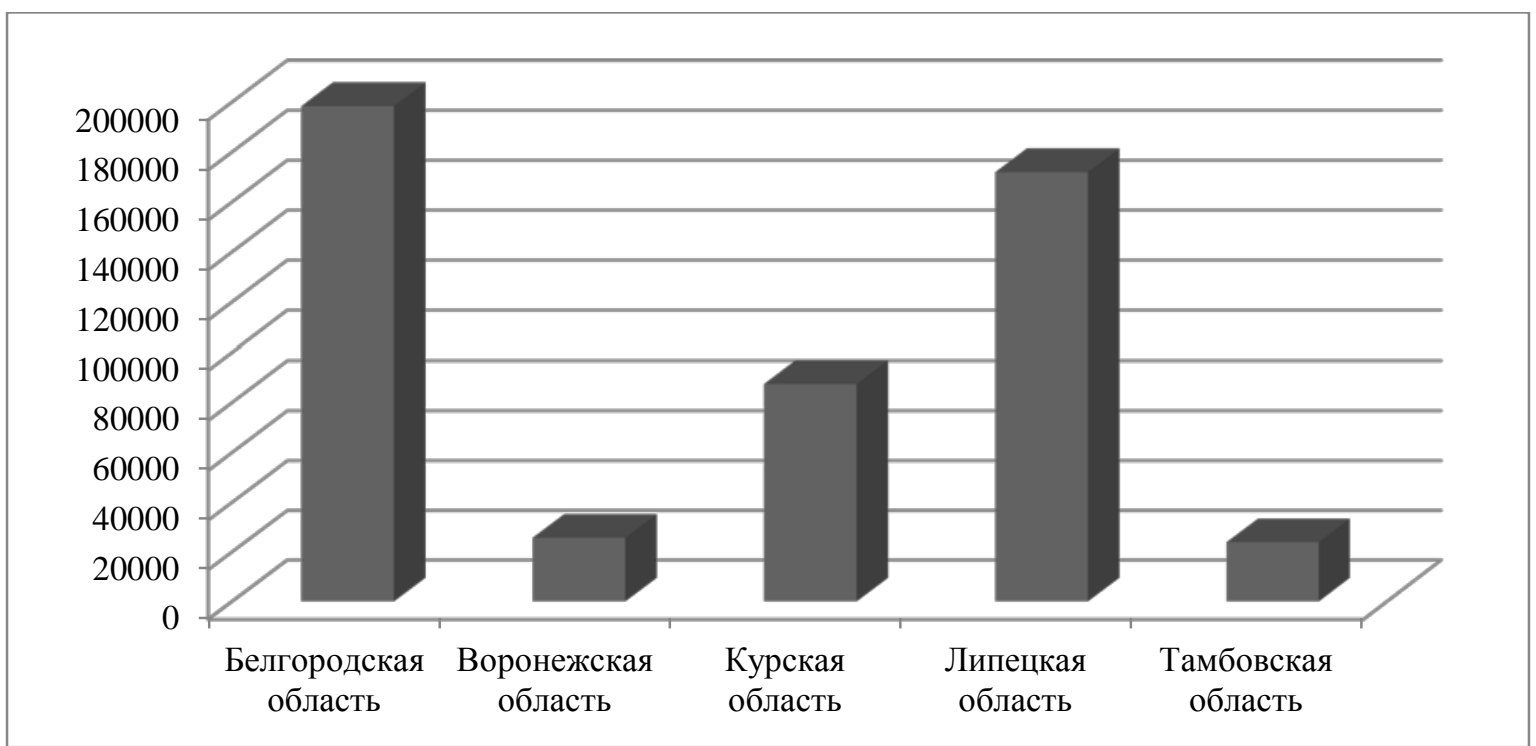

Рис. 3. Сальдированный финансовый результат экономической деятельности ЦентральноЧернозёмного макрорегиона в 2019 году, млн руб. [Белгородская область в цифрах, 2020] Fig. 3. Net financial result of economic activity of the Central Black Earth Macro-region in 2019, million rubles [Belgorod region in numbers, 2020]

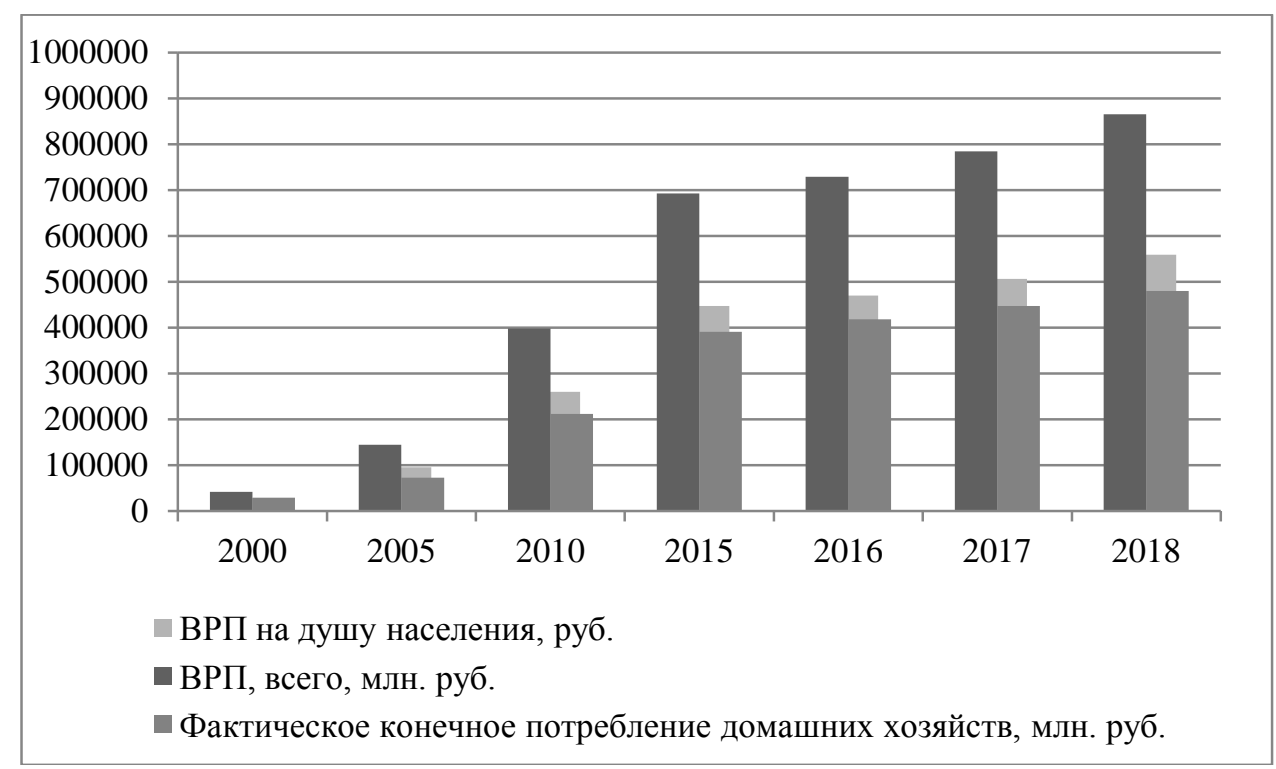

Рис. 4. Динамика ВРП Белгородской области за 2000-2018 годы [Белгородская область в цифрах, 2020]

Fig. 4. Dynamics of GRP of the Belgorod region for 2000-2018 [Belgorod region in numbers, 2020]

Обобщенной характеристикой экономической деятельности региона, характеризующей процесс производства товаров и услуг для конечного использования, является ВРП. Операции, относящиеся непосредственно к процессу производства, отражает счет производства, в котором можно выделить добавленную стоимость. Основная цена - цена, получаемая производителем за единицу товара или услугу, без налогов на продукты, но 
включая субсидии на продукты. Суммарную стоимость товаров и услуг, являющихся результатом производственной деятельности единиц-резидентов экономики в отчетном периоде, отражает выпуск товаров и услуг. Товары и услуги, которые полностью потребляются в процессе производства в отчетном периоде, представляют собой промежуточное потребление. Потребление основного капитала не входит в состав промежуточного потребления (таблица 1).

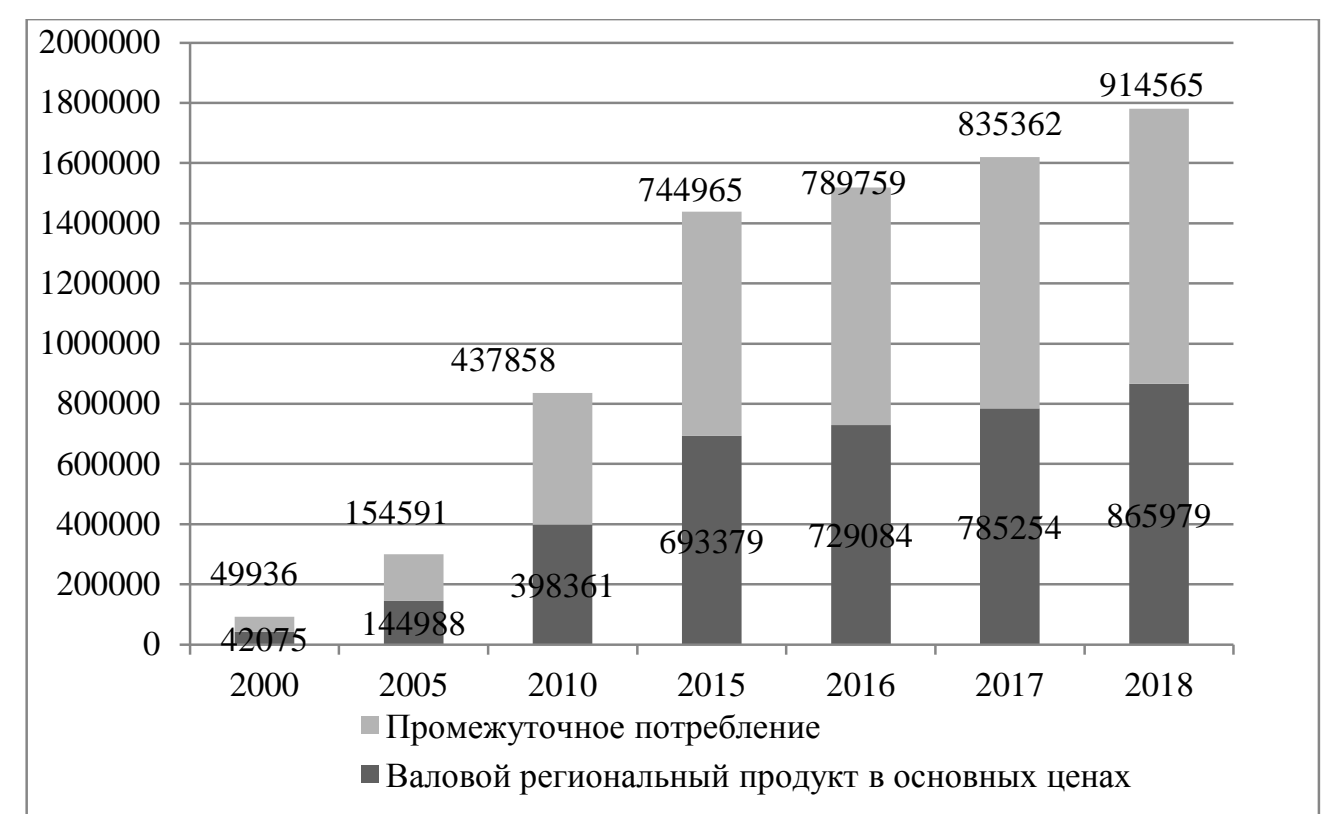

Рис. 5. ВРП Белгородской области по видам первичных доходов за 2000-2018 годы

(в текущих ценах; в процентах к итогу) [Белгородская область в цифрах, 2020]

Fig. 5. GRP of the Belgorod region by types of primary income for 2000-2018

(in current prices; as a percentage of the total) [Belgorod region in numbers, 2020]

Таблица 1

Table 1

Основные характеристики движения основных фондов (ОФ) Белгородской области в 2000-2018 гг.

Main characteristics of the movement of fixed assets in the Belgorod region in 2000-2018

\begin{tabular}{|l|l|l|l|l|l|l|l|}
\hline & 2000 & 2005 & 2010 & 2015 & 2016 & 2017 & 2018 \\
\hline Ввод в действие ОФ, млн руб. & 7614 & 26128 & 78382 & 88118 & 116504 & 140488 & 96748 \\
\hline Коэффициент обновления ОФ, \% & 4,9 & 8,8 & 11,7 & 6,9 & 8,4 & 9,4 & 6,2 \\
\hline Коэффициент выбытия ОФ, \% & 0,9 & 0,5 & 0,5 & 0,4 & 0,4 & 0,5 & 0,5 \\
\hline Степень износа ОФ, \% & 41,0 & 37,4 & 38,2 & 44,0 & 44,4 & 43,9 & 44,5 \\
\hline
\end{tabular}

Основные фонды - произведенные активы, подлежащие использованию неоднократно или постоянно в течение длительного периода, но не менее одного года, для производства товаров, оказания рыночных и нерыночных услуг, для управленческих нужд либо для предоставления другим организациям за плату во временное владение и пользование или во временное пользование. К основным фондам относятся здания, сооружения, машины и оборудование, транспортные средства, рабочий и продуктивный скот, многолетние насаждения, другие виды основных фондов.

Учетная стоимость основных фондов равна сумме учитываемых в бухгалтерских балансах организаций остаточной балансовой стоимости основных фондов и величины накопленного износа. Она отражает наличие основных фондов без учета постепенной утраты их потребительских свойств в процессе эксплуатации. Остаточная балансовая стоимость основных 
фондов отражает постепенную утрату их потребительских свойств в размере накопленного износа. Полная остаточная балансовая стоимость основных фондов учитывается в смешанных ценах, так как часть инвентарных объектов отражается в балансах предприятий по восстановительной стоимости на момент последней проведенной переоценки, а другая часть, не проходившая переоценок, - в ценах приобретения. Полная восстановительная стоимость основных фондов - это полная стоимость затрат на замену имеющихся основных фондов аналогичными им новыми объектами, определенных по ценам и тарифам, существующим на дату переоценки (рис. 6).

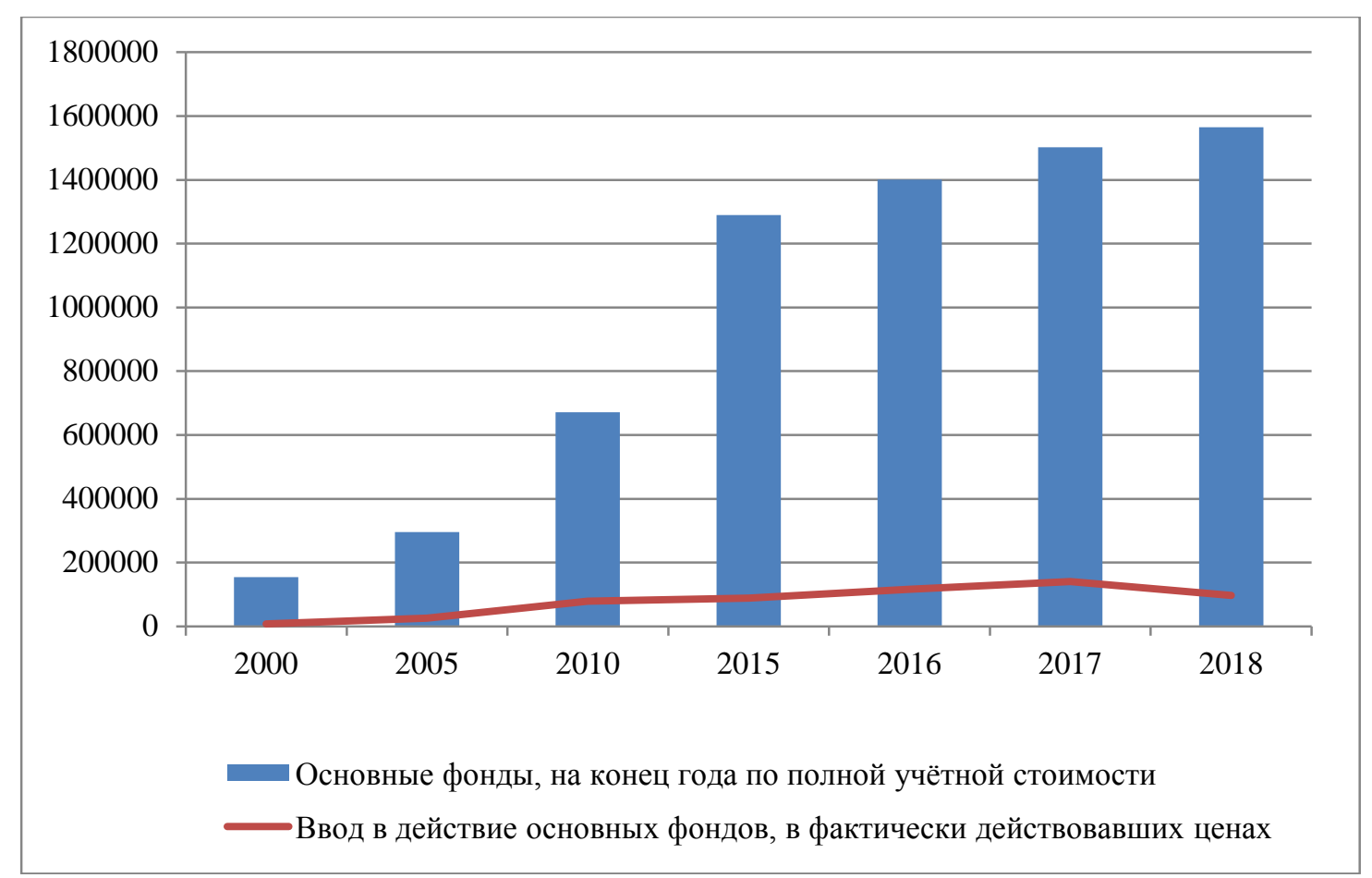

Рис. 6. Характеристика основных фондов Белгородской области за 2000-2018 годы

[Белгородская область в цифрах, 2020]

Fig. 6. Characteristics of fixed assets of the Belgorod region for 2000-2018

[Belgorod region in numbers, 2020]

На рисунке 6 заметна динамика основных фондов, исчисленных по полной учётной стоимости, однако с учётом корректировки по фактически действовавшим ценам показывает более сдержанные темпы роста. Ввод в действие основных фондов отражает стоимость законченных строительством и принятых в эксплуатацию в установленном порядке объектов строительства, а также оборудования, инструмента, инвентаря, многолетних насаждений, рабочего и продуктивного скота.

Коэффициент обновления основных фондов - это отношение основных фондов, введенных в действие в течение года, к их наличию на конец года, в процентах, отражающее удельный вес новых (введенных за год) основных фондов в их общем объеме. Коэффициент выбытия основных фондов - это отношение ликвидированных за год основных фондов к их наличию на начало года, в процентах, характеризующее интенсивность процесса обновления основных фондов. Частичная или полная утрата основными фондами потребительских свойств и стоимости в процессе эксплуатации под воздействием сил природы и вследствие технического прогресса - это износ основных фондов.

В условиях непрекращающихся преобразований и нарастающих геополитических стрессоров становится затруднительным прогнозирование любой хозяйственной системы. Пространственное развитие региональной экономики, происходящее под воздействием разнообразных стрессоров, результируется в весьма противоречивых эффектах для 
российской хозяйственной системы. Это выражается в том, что экономическая динамика демонстрирует как успехи, так и деструкции [Андреева, 2018]. Существующий разрыв в социально-экономическом развитии центральных и периферийных территорий необходимо устранять методами и инструментами пространственной политики.

Распространение отрицательных сетевых эффектов региональных систем формирует специфическую систему внерыночных механизмов, которые встраиваются в рыночные алгоритмы, изменяя их природу и формируя структурные элементы в региональных экономических системах, функционирующих по своим собственным законам [Зубаревич, 2015]. Это формирует динамическую несогласованность в пространственном развитии макрорегионов Российской Федерации. Такая несогласованность проявляется в виде необходимости активизации экономического роста на фоне одновременно существующей низкой производительности труда и роста уровня дифференциации доходов. Важным моментом для успешной реализации намеченных целевых ориентиров является достижение динамической согласованности осуществляемых действий.

\section{Заключение}

Подводя итог, следует выделить следующие тенденции и перспективы пространственного развития исследуемой территории:

1) концентрация экономического роста в ограниченном числе центров, рост социальноэкономической роли городов;

2) стабилизация численности населения в крупных субъектах Российской Федерации и закрепление перманентного характера в общей тенденции снижения численности населения периферийных территорий;

3) сокращение межрегиональных социально-экономических диспропорций в рамках глобальных центростремительных тенденций;

4) трансформация пространственной организации экономики в виде транспарентности экономических процессов.

Таким образом, анализ основных тенденций пространственного развития экономики Центрально-Чернозёмного макрорегиона позволяет видеть основные закономерности и тенденции, требующие значительного повышения способности к гибким реакциям и устойчивому развитию региональных систем, направленному на подъем пространственных эффектов территории.

\section{Список литературы}

1. Андреева О.В. 2018. Адаптивность российской экономики в мировом контексте: источники и исходы. Российский миттельшпиль: экономика, техногенез, геостратегия: Сборник тезисов выступлений Международной научной конференции. Под ред. Ю.М. Осипова, С.С. Нипа, Т.С. Сухиной. М.: Экономический факультет МГУ им М.В. Ломоносова: 9-11.

2. Белгородская область в цифрах. 2020: Кратк. стат. сб. Белгородстат, 244.

3. Белокрылова О.С., Киселева Н.Н. 2013. Институциональные изменения на рынке земли южных регионов. Пространство экономики. 4-3. URL: https://cyberleninka.ru/article/n/istitutsionalnyeizmeneniya-na-rynke-zemli-yuzhnyh-regionov (дата обращения: 24.09.2020).

4. Владыка М.В., Горбунова Е.И., Ермаченко Ф.М. 2019. Пространственные эффекты объединения территорий в макрорегионы. Научные ведомости Белгородского государственного университета. Серия: Экономика. Информатика. 46 (3): 383-390. DOI 10.18413/2411-3808-2019-46-3383-390.

5. Гранберг А.Г. 2009. О программе фундаментальных исследований пространственного развития России. Регион: экономика и социология. 2: 166-178.

6. Губанова Е.С., Клещ В.С. 2017. Методологические аспекты анализа уровня неравномерности социально-экономического развития регионов. Экономические и социальные перемены: факты, тенденции, прогноз. 10 (1): 58-75. 
7. Зубаревич Н.В. 2015. Стратегия пространственного развития после кризиса: от больших проектов к институциональной модернизации. Журнал новой экономической ассоциации. 2: 226-230.

8. Клейнер Г.Б. 2015. Государство - регион - отрасль - предприятие: каркас системной устойчивости экономики России. Часть 1. Экономика региона. 2: 50-58.

9. Минакир П.А. 2019. Дальневосточные институциональные новации: имитация нового этапа. Пространственная экономика. 1: 7-17.

10. Об утверждении Стратегии пространственного развития РФ на период до 2025 года: Распоряжение Правительства РФ от 13.02.2019 N 207-р. СПС «КонсультантПлюс»: Законодательство: Версия Проф. URL: http://base.consultant.ru (дата обращения: 18 сентября 2020).

11. Krugman, P.R., Masahisa Fujita, Anthony J.V. 1999. The Spatial Economy: Cities, Regions and International Trade. The MIT Press, London, 367.

12. Official statistical methodology: definitions of fixed capital investments at the Federal level. 2020. Available at: https://www.gks.ru/free_doc/new_site/ business /invest/ met-inv-fed.pdf (accessed 23.09.2020).

13. Stryabkova E., Zakharov V., Vladyka M., Kulik A., Kogteva A., Nuridzhanov A. 2018. Identification of long range growth poles as a key instrument of the federal policy of Russia's regional territories. Amazonia Investiga. 7(17): 433-442. Available at: http://www.udla.edu.co/revistas/index.php/ amazonia - investiga (accessed 23.09.2020).

14. Strange W.C. 2009. Viewpoint: Agglomeration research in the age of disaggregation. Canadian Journal of Economics. Revue canadienne d'econjmique. 42 (1): 1-27.

15. Vasilieva, A.V., Morozova T., Shlapeko E. 2018. Contribution of international scientific cooperation into cross-border development (case of the Republic of Karelia). Practical Geography and XXI Century Challenges. International Scientific and Practical Conference, 4-6 June 2018, Moscow. Conference Book. Moscow: Institute of Geography, Russian Academy of Sciences, 455.

16. Wandel C. 2010. Industry agglomerations and regional development in Hungary: economic processes during European integration. Peter Lang, 278.

\section{References}

1. Andreeva O.V. 2018. Adaptability of the Russian economy in the global context: sources and outcomes. Russian mittelspiel: economy, technogenesis, geostrategy: Collection of abstracts of international scientific conference presentations. Edited by Yu.M. Osipov, S.S. NIPA, T.S. Sukhina. M.: Faculty of Economics of Lomonosov Moscow State University: 9-11. (in Russian)

2. Belgorod region in numbers. 2020: Brief introducti. stat. sat. Belgorodstat, 244. (in Russian)

3. Belokrylova O.S., Kiseleva N.N. 2013. Institutional changes in the land market in the southern regions. Economy space. 4-3. Available at: https://cyberleninka.ru/article/n/istitutsionalnye-izmeneniya-narynke-zemli-yuzhnyh-regionov (accessed 24.09.2020). (in Russian)

4. Vladyka M.V., Gorbunova E.I., Ermachenko F.M. 2019. Spatial effects of the unification of the territories in the regions. Belgorod State University Scientific Bulletin. Economics. Information Technologies. 46(3): 383-390. (in Russian). DOI 10.18413/2411-3808-2019-46-3-383-390.

5. Granberg A.G. 2009. About the program of fundamental research of spatial development of Russia. Region: Economics and Sociology. 2: 166-178. (in Russian)

6. Gubanova E.S., Kleshch V.S. 2017. Methodological aspects of analyzing the level of uneven socioeconomic development of regions. Economic and Social Changes: Facts, Trends, Forecast. 10(1): 58-75. (in Russian)

7. Zubarevich N.V. 2015. The strategy of spatial development after the crisis: from large projects to institutional modernization. Journal of the New Economic Association. 2: 226-230. (in Russian)

8. Kleiner G.B. 2015. State-region-industry-enterprise: a framework for system stability of the Russian economy. Part 1. Regional economy. 2: 50-58. (in Russian)

9. Minakir P.A. 2019. Far Eastern institutional innovations: imitation of a new stage. Spatial Economics. 1: 7-17. (in Russian)

10. About the Approval of the Strategy of Spatial Development of the Russian Federation for the period up to 2025: the Order of the Government of the Russian Federation of 13.02.2019 N 207-p. ATP "Consultant plus": Legislation: Prof Version. Available at: http://base.consultant.ru (accessed 18 September 2020)

11.Krugman, P.R., Masahisa Fujita, Anthony J.V. 1999. The Spatial Economy: Cities, Regions and International Trade. The MIT Press, London, 367.

12. Official statistical methodology: definitions of fixed capital investments at the Federal level. 2020. Available at: https://www.gks.ru/free_doc/new_site/ business /invest/ met-inv-fed.pdf (accessed 23.09.2020). 
13.Stryabkova E., Zakharov V., Vladyka M., Kulik A., Kogteva A., Nuridzhanov A. 2018. Identification of long range growth poles as a key instrument of the federal policy of Russia's regional territories. Amazonia Investiga. 7(17): 433-442. Available at: http://www.udla.edu.co/revistas/index.php/ amazonia - investiga (accessed 23.09.2020).

14.Strange W.C. 2009. Viewpoint: Agglomeration research in the age of disaggregation. Canadian Journal of Economics. Revue canadienne d'econjmique. 42 (1): 1-27.

15.Vasilieva, A.V., Morozova T., Shlapeko E. 2018. Contribution of international scientific cooperation into cross-border development (case of the Republic of Karelia). Practical Geography and XXI Century Challenges. International Scientific and Practical Conference, 4-6 June 2018, Moscow. Conference Book. Moscow: Institute of Geography, Russian Academy of Sciences, 455.

16. Wandel C. 2010. Industry agglomerations and regional development in Hungary: economic processes during European integration. Peter Lang, 278.

\section{ИНФОРМАЦИЯ ОБ АВТОРАХ}

Владыка Марина Валентиновна, доктор экономических наук, доцент, профессор кафедры прикладной экономики и экономической безопасности Белгородского государственного национального исследовательского университета, Белгород, Россия

Солнцев Денис Романович, консультант отдела проектной деятельности управления ресурсного обеспечения Департамента агропромышленного комплекса и воспроизводства окружающей среды Белгородской области

\section{INFORMATION ABOUT THE AUTHORS}

Marina V. Vladyka, Doctor of Economic Sciences, Associate Professor, Professor of the Department of Applied Economics and Economic Security Belgorod National Research University, Belgorod, Russia

Denis R. Solntsev, Consultant of the Department of Project Activities of the Resource Support Department of the Department of Agroindustrial Complex and Environmental Reproduction of the Belgorod Region, Belgorod, Russia 